\title{
Case Study of Rip Current Knowledge amongst Students Participating in a Study Abroad Program
}

\author{
Chris Houser \\ University of Windsor
}

\section{Robert Brander}

UNSW Australia

\section{Christian Brannstrom, Sarah Trimble, and Jane Flaherty Texas A\&M University}

Rip currents are narrow seaward-flowing currents common on many global beaches and are capable of transporting even experienced swimmers a significant distance offshore, placing them at risk of needing rescue or drowning. In this respect, rips represent a significant hazard to beach users around the world (e.g. Klein et al., 2003; Scott et al., 2009; Gensini \& Ashley, 2010; Houser et al., 2011; Barrett \& Houser, 2012; Brighton et al., 2013; Arun Kumar \& Prasad, 2014; Barlas \& Beji, 2016) and are recognized as a major health problem that can have serious social and economic impacts for recreational beach users (Short \& Hogan, 1994; Sherker et al., 2008; Morgan et al., 2009; Sherker et al., 2010). Rips are a particular threat to inexperienced and uninformed beach users, with the potential for drowning associated with gender, age, overconfidence in swimming ability, alcohol consumption, and an inability to spot a rip current (Morgan et al., 2009). Recent surveys from Florida (Caldwell et al., 2013) and Texas (Brannstrom et al., 2014; Brannstrom et al., 2015) suggest that few beach users are able to correctly identify a rip current. Therefore, the level of "hazard" that rip currents represent is dependent on whether beach users recognize and obey safety information and warning flags (Wilks et al., 2007; Matthews et al., 2014; Brannstrom, et al, 2015), and whether they understand the potential for rip occurrence on a beach. Even experienced swimmers can be unexpectedly caught in a rip if they are not familiar with a beach, and may drown if they panic and become exhausted from fighting against the current (Brander \& MacMahan, 2011).

Tourists and overseas visitors are more susceptible to drowning in rip currents because of their limited knowledge and limited awareness of beach hazards and safety (Wilks et al., 2007; Williamson et al, 2012). This group includes students participating in study abroad or foreign exchange programs. Many universities encourage student participation in study abroad programs, which may be located in cities or study centers close to surf beaches prone to the occurrence of rip currents. Students may visit beaches as an official part of the trip or as an optional activity not formally linked to the study abroad program, and visits may happen with or without supervision by the faculty member leading the trip. In recent years, a number of highly publicized drownings involving students studying abroad have occurred in Costa Rica, including the 2011 drowning of three 
teenagers from Ohio on a study abroad trip that included an unscheduled stop at Playa Bejuco on the central Pacific Coast (see Arozarena et al., 2015). In another case, three students and their teacher from Kansas were swept offshore at Playa Palo Seco (just south of Playa Bejuco) and drowned in the heavy surf while on a Spanish-language immersion trip (see Arozarena et al., 2015). It is important to note that these are not isolated cases that only occur in Costa Rica; student drownings abroad can, and have, occurred in other countries where students have an opportunity to visit a beach.

Reducing the number of drownings by students depends on an understanding of their knowledge about rip currents and their behavior when visiting a foreign beach that may lack posted safety information or warning flags. Faculty directors and program staff can play a role in reducing drownings by providing students with rip current information in advance of a study abroad trip that visits a beach or when the group will be staying near a beach. Posted warnings are highly variable globally, ranging from a flag system in Australia to sporadic NOAA (National Oceanographic and Atmospheric Administration) warning signs in Costa Rica, to complete absence of warnings on Brazilian beaches. As a result, study abroad students may confront inconsistent warning systems on unfamiliar beaches that typically lack lifeguards. This brief communication describes results of the first survey of students studying abroad from the United States $(n=358)$ to determine their knowledge about rip currents and other beach hazards, and to determine their behavior, choices, and precautions taken when visiting a beach during their time abroad. Results are intended to motivate the improvement of beach safety education provided to students studying abroad.

\section{Methodology}

The research design for this study, approved by the relevant human subject protection program from Texas A\&M University, relied on an internet-based survey instrument sent by email to all undergraduate and graduate students from Texas A\&M University who participated in a study abroad program between May 2013 and May 2015 (see Appendix 1). Our survey consisted of questions re-phrased from Sherker et al. (2010), and photograph-based rip current identification protocols modified from Brannstrom et al. (2014), with questions grouped into six categories (Table 1). Potential respondents were recruited by email in May 2015 from a database maintained by the Texas A\&M University Study Abroad Program Office. The survey remained open from May 2015 until August 2015, and answers were recorded anonymously. A copy of the survey is provided as an appendix to this manuscript. During analysis, chi-square tests $\left(\chi^{2}\right)$ were performed to determine if some groups of students (i.e., short v. long term abroad) had statistically significant traits. Notable results from these analyses are indicated by their $\chi^{2}$ value and significant $p$ value in the following results. 
Table 1. Question groups used to elicit responses from Texas A\&M University students who participated in a study abroad program between May 2013 and May 2015.

\begin{tabular}{lll}
\hline Group & Focus of Questions & Example topics \\
\hline 1 & Non-identifying personal information & ZIP code, age, ethnicity, and swimming self-assessment \\
2 & Academic information & Major and classification \\
3 & Study abroad information & Country and type of study abroad program \\
4 & Beach use information & Frequency of visits; whether beach visit was required \\
5 & $\begin{array}{l}\text { Perceived hazards and precautions taken during } \\
\text { beach visits }\end{array}$ & $\begin{array}{l}\text { Whether students noticed any signage } \\
\text { Knowledge of rip currents and beach dynamics }\end{array}$ \\
\hline
\end{tabular}

\section{Results}

A total of 298 undergraduate students and 60 graduate students completed the online survey between May and August 2015. The majority of students ( $n=220,68 \%$ ) participated in a faculty-led program, with the remainder participating in a program not led by a (specific) faculty member $(n=83,26 \%)$, an internship $(n=12,4 \%)$, or a service-learning trip ( $n=9,3 \%)$. Most student respondents participated in the study abroad for credit $(n=250,77 \%)$. The length of the study abroad programs varied from less than 2 weeks $(n=93,29 \%)$ to a full semester ( $n=84,26 \%$ ), with fairly equal distribution of respondents amongst program lengths. Demographic data for the students participating in the survey are provided in Table 2, and a list of the regions visited by the students participating in the survey are provided in Table 3.

Table 2. Demographic data of student respondents participating on a study abroad between May 2013 and May 2015.

\begin{tabular}{|c|c|c|}
\hline & & \# of Students \\
\hline \multirow[t]{2}{*}{ Gender } & Male & 56 \\
\hline & Female & 141 \\
\hline \multirow[t]{6}{*}{ School Year } & Freshman ( $1^{\text {st }}$ year $)$ & 34 \\
\hline & Sophomore ( $2^{\text {nd }}$ year $)$ & 60 \\
\hline & Junior ( $3^{\text {rd }}$ year) & 106 \\
\hline & Senior ( $4^{\text {th }}$ year $)$ & 58 \\
\hline & Super Senior $\left(5^{\text {th }}\right.$ year $)$ & 8 \\
\hline & Graduate & 57 \\
\hline \multirow[t]{4}{*}{ Program Type } & Faculty led & 220 \\
\hline & Service Learning Trip & 9 \\
\hline & Internship & 12 \\
\hline & Other & 83 \\
\hline
\end{tabular}


Table 3. Regions visited by the students participating in the survey during their time abroad.

\begin{tabular}{lll}
\hline Region & \# of Responses & \% of Responses \\
\hline Africa & 21 & 6 \\
Asia & 33 & 10 \\
Australia and New Zealand & 11 & 3 \\
Canada & 5 & 2 \\
Central America and Caribbean & 68 & 21 \\
Europe & 155 & 48 \\
Middle East & 11 & 3 \\
South America & 20 & 6 \\
\hline
\end{tabular}

The majority of respondents (74\%) visited at least one beach during their study abroad experience, and 64\% of students visited more than one beach. The number of beaches visited does not exhibit a statistically significant relationship with the length of the study abroad program, but instead is dependent on the school year classification: junior students are significantly more likely to visit two to five beaches $(\chi 2=23.95, \varrho<0.00)$. For a majority of students who visited a beach, the visit was not an official part of the study abroad program and occurred during free time ( $\mathrm{n}=175$, $66 \%$ ), with more students than expected visiting only one beach as part of an optional activity $\left(\chi^{2}=15.51, \varrho<0.00\right)$. Based on the associated free response answers, the unofficial trips to the beach (i.e., a trip not associated with the study abroad program) were impromptu decisions based on information provided by other students, tourists, the professor, and/or guides. One student was "invited by a friend" to visit a beach, while another respondent "visited Barcelona on holiday" and made a visit to the beach. "Free days" and "time off" from the program presented opportunities for students to travel to nearby beaches. One student reported that she "heard about it [the beach] from tourists and decided that a relaxing day at the beach sounded really nice." Another student commented that the "bus driver recommended" a visit to a particular beach. Others noted that they "had a free day and heard a previous group had gone to the beach so we decided to go", or visited a beach based on the "Suggestions from [the] professor and word of mouth." None of the students identified safety as a motivating factor for selecting a particular beach to visit.

Students who only visited one beach were more likely to self-rate their ability to swim in open water as $<100$ yards without having to stop or pause $(\chi 2=25.54, \varrho<0.00)$. Students who visited only one beach were also more likely to go as part of a large group (defined as more than five other students; $\chi^{2}=18.03, \varrho=0.02$ ). Unofficial trips to the beach tended to be completed as part of a group with more than five participants $(n=180,86 \%)$, with only three students noting that they went to the beach alone. Nearly half of participants $(45 \%)$ noted that their group included other tourists, locals of students from a different study abroad program, suggesting that the decision to visit a beach and beach selection were not made solely by the individual students. Free responses suggest that selection of the beach was based on convenience (distance from where they were staying) and the use of "we" suggests that decisions were made as a group; for example, representative responses from the students suggest that the beach was "across the street," "near," or a "short walk" from the hotel they were using on a visit to a coastal city, providing easy opportunity for entering the water. Other examples include: "It was across the street from the resort hotel where we were staying", and 
"our Hotel was by the ocean. We had a few hours free, and some members of the group decided to visit the beach". Only seven students $(3 \%)$ selected a beach based on the presence of lifeguards. It is not clear how and why those particular students made a decision based on safety.

The majority of students who visited a beach as an official part of their study abroad noted that it was part of "designated recreation time", in which participation was optional. One student noted that the beach visit "was the day's scheduled activity. Students had paid for it as part of their course fees, but could opt out if they wanted to", while another noted, "we stopped along the way at different beaches and we could get out and go to the water if we wanted to." Since this survey focused only on students, it is not clear how and why faculty members make decisions to visit beaches during their study abroad.

Although the majority of surveyed students visited a beach during their study abroad, 59\% $(n=156)$ did not receive beach safety information prior to or during their study abroad trip. Of those who did receive beach safety information $(n=54,26 \%)$, the majority received it through a lecture or presentation given by the faculty member or a guest lecturer during or prior to their trip ( $\mathrm{n}=48$, $74 \%)$. Some also visited the beach to complete observations or participate in a lecture $(n=36)$ related to either tourism or physical geography.

A large number of students either did not see beach safety information posted at the beaches they visited ( $n=98,59 \%$ of responses) or did not remember seeing safety information ( $n=29,18 \%$ ). Several of those students were unsure of the safety message(s), offering responses indicating that cultural and language differences may have impeded understanding of safety information. For example, one student indicated "there might have been [safety information], but it was in Italian." Another responded: "At one of the beaches that we had to pay an entry fee to because it was maintained by some level of government, it seemed liked there were probably safety notices posted at the entrance." Finally, one respondent indicated that "there were [warning] signs everywhere (like in the States), but we didn't typically stop and read [the signs]." Others who remembered seeing a warning sign noted that they were associated with hazards other than rip currents, including sharks, weather, boats, diving and tides, or that there were no lifeguards present. Several noted that the area where they chose to enter the water was relatively remote with responses such as "rainforests don't have signs", and "No...this was where the desert meets the gulf." Consistent with the observations about beach safety information, $76 \%$ of respondents did not remember seeing a lifeguard at any of the beaches that they visited and only one respondent described a lifeguard intervention, indicating "lifeguards talked to the class before letting anyone enter the beach."

More than $60 \%$ of respondents $(n=126)$ did not take precautions before visiting the beach, although many of those who took precautions were not cautious about the water. The most popular precautions were sunscreen and sandals, robbery prevention, and guards/guides for personal protection. While the majority of respondents did not take precautions with regards to swimming, a relatively small number noted the importance of checking the water before entering. Some respondents indicated the need for "checking the flag at the beach to make sure the water is safe," "not going to [sic] deep," "[looking] for rocks." Another respondent noted that they "evaluated the wave size and weather for safety, as well as water clarity." While most students did not experience 
difficulty while swimming ( $\mathrm{n}=186,71 \%$ ), several noted that they experienced difficulty as a result of large waves $(n=11,4 \%)$ or strong currents $(n=14,5 \%)$.

Most respondents who visited a beach during their study abroad had heard of rip currents $(n=182,69 \%)$ and several students had previously been caught in a rip current $(n=47,18 \%)$. Of these, most knew to swim parallel to the beach to escape the rip. The majority $(68 \%)$ of students who had heard of rip currents believed that a rip is not visible and that they would not be able to spot a rip current. Even those who had previously been caught in a rip current believed that they would not be able to spot a rip current or they could only do so "sometimes." However, when presented with rip current photographs, the majority of respondents who visited a beach abroad were able to select areas away from rip currents as areas that they "would feel most safe to enter the water" (Table 4; Figure 1). A relatively small number of students selected the rip current as a safe place to enter the water: $24 \%$ in photograph 1, 16\% in photograph 2, and 17\% in photograph 3 . However, a large number of students selected areas directly adjacent to the rip as being a safe place to enter the water (16\% in photograph $1,39 \%$ in photograph 2 , and $31 \%$ in photograph 3$)$. These students may still place themselves in hazardous conditions, particularly where the rip is not as distinct visually (photographs 2 and 3 ).

Figure 1. Identified location of safest location to enter the water in the photographs presented in Questions 41 (a), 42 (b) and 43 (c).
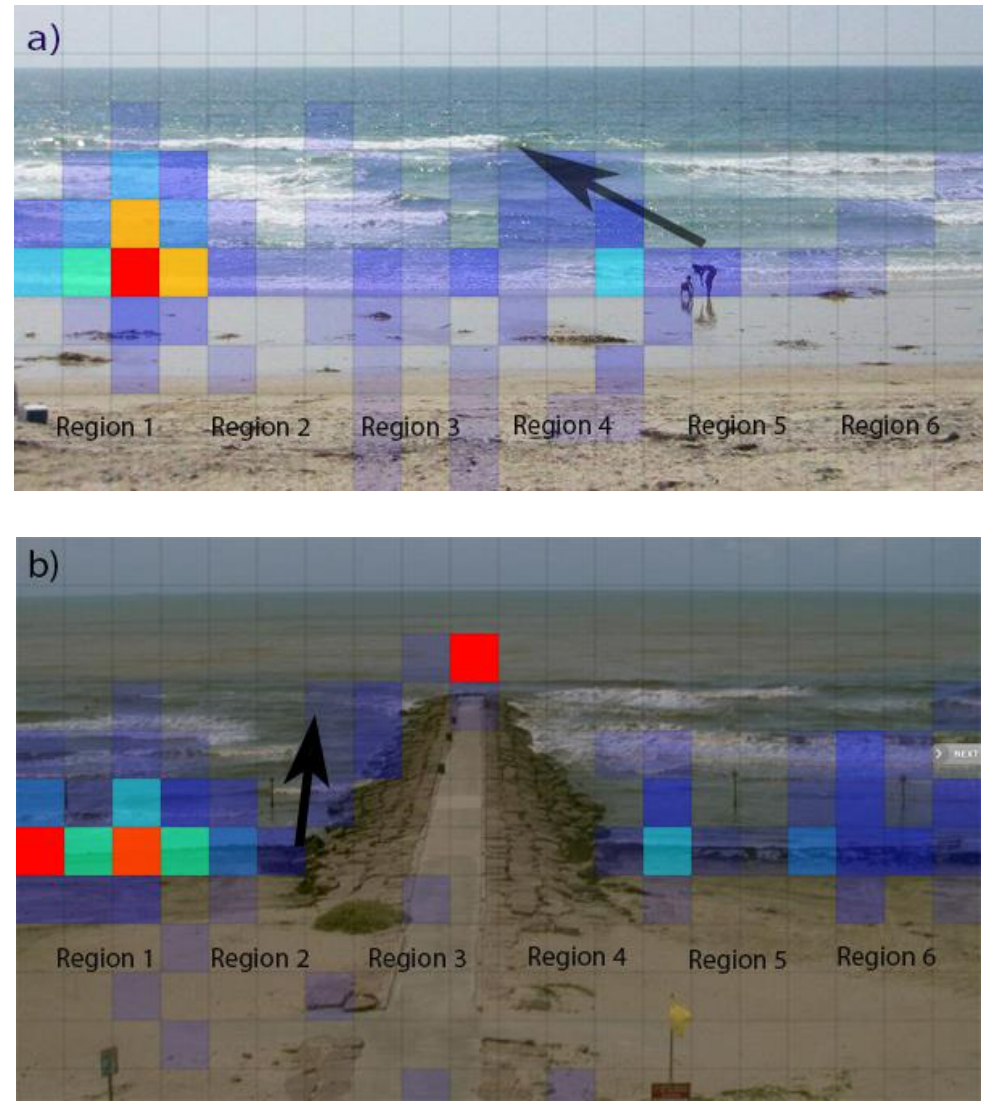


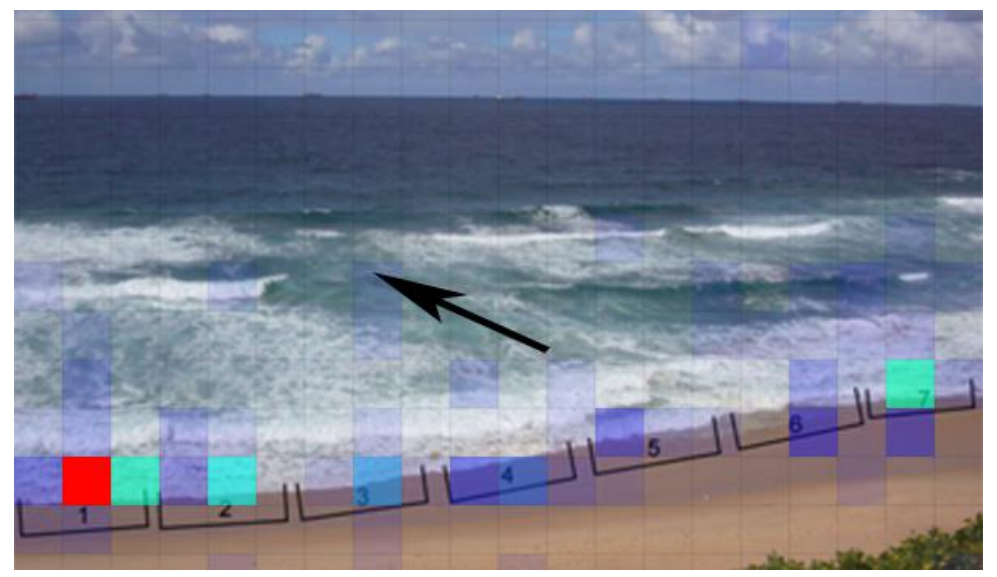

Identified location of safest location to enter the water in the photographs presented in Questions 41 (a), 42 (b) and 43 (c). Warm (red) colors indicate large number of responses, while cold (blue) colors indicate few responses. No color (background picture) represents areas that received no responses. The location of the rip current in each photograph is shown with the black arrow. Note that the arrow, grid system or references to the regions were not presented to the students.

\section{Discussion and Conclusions}

Study abroad programs are an increasingly promoted part of the university undergraduate curriculum in the United States, intended to provide students with a global perspective and an opportunity to conduct problem-oriented fieldwork that leads to transferable skills in project design, organization, leadership and group dynamics. However, the location and the nature of some programs makes it necessary to ensure that students are informed about potential hazards, such as rip currents, and the strategies to reduce their exposure to potential hazards. This requires that students be informed about the conditions that may affect their safety and wellbeing while abroad. Of course, universities cannot eliminate all risks or assume that all students will use the information provided to them by the institution or the faculty leading the trip. Improving safety of students abroad and developing effective educational material, therefore, depends on an understanding of student knowledge of rip currents and other beach hazards, and their behavior at foreign beaches, both individually and as part of a group.

Results of this preliminary study suggest that students who visit areas with beaches tend to visit one or more beaches during their time abroad and tend to make impromptu decisions based on information provided by other students, tourists, academic staff, and guides. Beach visitation decisions appear to be made as a group and are based largely on convenience rather than on whether the beach conditions are safe or lifeguards are present, which suggests that unknown group dynamics and leadership traits influence decision-making, possibly influenced by impaired or poor judgment that is commonly observed among students studying overseas. A statistically significant number of students who visited only one beach did so as an optional part of their trip with a relatively large group, and had a lower self-rated ability to swim in open water. This group of students may be at greater risk of drowning or needing rescue because their decisions to visit a beach and enter the water may not be based on ability to swim, or on evaluation of surf hazards, but are instead guided by peer influence. The apparent importance of peer influence identified in the present study is consistent with other studies that suggest peer influence is related to risk-taking 
amongst students (Rolison \& Scherman, 2003), including but not limited to speeding (Møller \& Haustein, 2014), alcohol use (Kim \& Kim, 2012) and substance abuse (Mason et al., 2014). It is important, however, to recognize that this survey did not include questions about these harmful behaviors and that no participation in other harmful activities (i.e., drinking or substance abuse) by the study abroad students who responded to this survey is intended. The propensity of college students to participate in risky behaviors, guided by peer participation, sensation-seeking and perceived benefits (Rolison \& Scherman, 2003), means it is imperative that students are provided with beach safety education if the official residence abroad is near a coast. It is also important in these instances for faculty leading a study abroad program to make clear distinctions between "program time" and "non-program time" to avoid ambiguity about the nature of the beach visit and place additional responsibility on the student making potentially risky decisions.

When the beach visit was an official part of the study abroad trip, it tended to be identified as "designated recreation time" in which their participation (in the water) was optional. Very few students received safety information prior to or during their trip abroad, and most did not remember seeing safety information posted at the beaches that they visited. Only students who visited the beach to complete observations or participate in a lecture tended to receive beach safety information during or prior to their trip. It is, however, possible that beach safety information was not posted because the beach was relatively calm and considered "safe." Subsequent studies should consider the type of beach that the students visited to potentially isolate the responses of students who visited a beach that was rip-prone from those that visited a relatively safe beach.

While most students reported taking precautions during their visit to the beach, they tended to focus on hazards other than rip currents and dangerous surf. Most of the respondents had heard of rip currents and several had previously been caught in a rip current, only a small number of students took precautions with respect to waves, weather, and currents before entering the water. This suggests that the majority of Texas A\&M University students studying abroad were not prepared for surf and rip hazards that may have been present on the beaches that they visited. Even if warning signs and flags were posted, the risk could only be minimized if students recognized and obeyed the safety information and warning flags (Wilks et al., 2007; Matthews et al., 2014; Brannstrom et al., 2014). This is a particular problem in countries where signs may be in other languages, use unfamiliar symbols, or use warning flags different to those in the United States. For example, many beaches in the United States use flags to warn about the surf hazard (e.g. green; calm, red: hazardous), while in Australia a pair of red and yellow flags are used to designate areas lifeguards believe to be (relatively) safe to swim (Sherker et al., 2010).

While it is not possible to warn students studying abroad about every possible hazard they may encounter when visiting a beach, it is possible to inform them about hazards and how to conduct themselves in a safe manner. The majority of students did not believe that rip currents were visible, but most were able to identify the relatively safe locations of the beach in the photographs. This suggests that they already have some basic ability to discriminate between safe and unsafe areas of the beach consistent with the observations of Sherker et al. (2010), who noted that beach users who have some basic knowledge about rip currents are more likely to avoid swimming in areas with a rip. This suggests that providing students participating on a study abroad with some basic education on rip currents and other surf hazards could prevent drownings and the need for rescues. If the study 
abroad program does not include any information related to the beach or beach communities as official parts of the program, the hazard can be mitigated if the students do not stay in hotels near the beach or have "designated recreation time" in close proximity to a beach.

The results of this study suggest that there is an additional need to provide support for faculty and program staff on rip safety. Information on rip safety is presently available from the National Weather Service of the United States (http://www.ripcurrents.noaa.gov/). Faculty and program staff can discuss beach hazards in pre-trip information sessions including a group discussion about personal swimming ability and experience, as well as stressing the importance of only going to beaches with lifeguards and with life-saving equipment. Program leaders should encourage students to seeking safety information and surf forecasts while planning beach visits. However, it is important to note that no standardized and devoted education and training materials related to beach safety presently exist that any university faculty and program staff can access and present to their students. Anecdotal information suggests that while pre-trip information sessions on beach hazards are common amongst study abroad institutions, the nature of these sessions can vary greatly in terms of content and application. In this regard, it is hoped that this pilot study not only brings attention to this situation, but that the survey be expanded to other universities both within and outside the United States.

\section{References}

Arun Kumar, S. A., Prasad, K. V., (2014). Rip current-related fatalities in India: A new predictive risk scale for forecasting rip currents. Natural Hazards. 70(1), 313-35.

Arozarena, I., Houser, C., Echeverría, A. G., Brannstrom, C., (2015). The rip current hazard in Costa Rica. Natural Hazards. 77(2), 753-68.

Barlas, B., Beji, S., (2016). Rip current fatalities on the Black Sea beaches of Istanbul and effects of cultural aspects in shaping the incidents. Natural Hazards. 80(2), 811-21.

Barrett, G., Houser, C., (2012). Identifying hotspots of rip current activity using wavelet analysis at Pensacola Beach, Florida. Physical Geography, 33(1), 32-49.

Brander, R. W., MacMahan, J. H., (2011). Future challenges for rip current research and outreach. In Leatherman, S. \& Fletemeyer, J., (eds). Rip Currents, Beach Safety, Physical Oceanography and Wave Modeling, (pp. 1-29). Boca Raton, FL: CRC Press.

Brannstrom, C., Trimble, S., Santos, A., Brown, H. L., Houser, C., (2014). Perception of the rip current hazard on Galveston Island and North Padre Island, Texas, USA. Natural Hazards, 72(2), 1123-1138.

Brannstrom, C., Brown, H. L., Houser, C., Trimble, S., Santos, A., (2015). "You can't see them from sitting here": Evaluating beach user understanding of a rip current warning sign. Applied Geography. $56,61-70$.

Brighton, B., Sherker, S., Brander, R., Thompson, M., Bradstreet, A., (2013). Rip current related drowning deaths and rescues in Australia: 2004-2011. Natural Hazards and Earth System Sciences $13,1069-1075$.

Caldwell, N., Houser, C., Meyer-Arendt, K., (2013). Ability of beach users to identify rip currents at Pensacola Beach, Florida. Natural Hazards, 68, 1041-1056.

Gensini, V. A., Ashley, W. S., (2010). An examination of rip current fatalities in the United States. Natural Hazards, 54, 159-175.

Houser, C., Barrett, G., Labude, D., (2011). Alongshore variation in the rip current hazard at Pensacola Beach, Florida. Natural Hazards, 57, 501-523.

Kim, J. H. \& Kim, K. S. (2012). The role of sensation seeking, perceived peer pressure, and harmful alcohol use in riding with an alcohol-impaired driver. Accident Analysis \& Prevention, 48, 326-334.

Klein, A. H., Santana, G. G., Diehl, F. L., De Menezes, J. T., (2003). Analysis of hazards associated with 
sea bathing: Results of five years work in oceanic beaches of Santa Catarina state, southern Brazil. Journal of Coastal Research, 19(1), 107-16.

Mason, M. J., Mennis, J., Linker, J., Bares, C., Zaharakis, N., (2014). Peer attitudes effects on adolescent substance use: The moderating role of race and gender. Prevention science, 15(1), 56-64.

Matthews, B., Andronaco, R., Adams, A., (2014). Warning signs at beaches: Do they work?. Safety science, 62, 312-8.

Møller, M., Haustein, S., (2014). Peer influence on speeding behaviour among male drivers aged 18 and 28. Accident Analysis \& Prevention, 64, 92-9.

Morgan, D., Ozanne-Smith, J., Triggs, T., (2009). Self-reported water and drowning risk exposure at surf beaches. Australian and New Zealand Journal of Public Health, 33(2), 180-88.

Primack, B. A., Kim, K. H., Shensa, A., Sidani, J. E., Barnett, T. E., Switzer, G. E., (2012). Tobacco, marijuana, and alcohol use in university students: a cluster analysis. Journal of American College Health, 60(5), 374-86.

Rolison, M. R. \& Scherman, A. (2003). College student risk-taking from three perspectives. Adolescence, 38 (152), 689.

Scott, T., Russell, P., Masselink, G., Wooler, A., (2009). Rip current variability and hazard along a macrotidal coast. Journal of coastal research, 56, 895.

Sherker, S., Brander, R., Finch, C., Hatfield, J., (2008). Why Australia needs an effective national campaign to reduce coastal drowning. Journal of Science and Medicine in Sport, 11(2), 81-3.

Sherker, S., Williamson, A., Hatfield, J., Brander, R., Hayen, A., (2010). Beachgoers' beliefs and behaviours in relation to beach flags and rip currents. Accident Analysis and Prevention, 42, 17851804

Short, A. D., Hogan, C. I., (1994). Rip currents and beach hazards: their impact on public safety and implications for coastal management. Journal of Coastal Research, SI12, 197-209.

Wilks, J., de Nardi, M., Wodarski, R., (2007). Close is not close enough: drowning and rescues outside flagged beach patrol areas in Australia. Tourism in Marine Environments, 4, 57-62.

Williamson, A., Hatfield, J., Sherker, S., Brander, R., Hayen, A., (2012). A comparison of attitudes and knowledge of beach safety in Australia for beachgoers, rural residents and international tourists. Australian and New Zealand Journal of Public Health, 36, 385-391. 


\section{Appendix: Survey}

\section{Texas A\&M University Survey of Beach Safety}

You are invited to take part in a research study being conducted by Sarah Trimble and Dr. Chris Houser from the College of Geosciences at Texas A\&M University. The information in this form is provided to help you decide whether or not to take part. If you decide to take part in the study, you will be asked to sign this consent form. If you decide you do not want to participate, there will be no penalty to you, and you will not lose any benefits you normally would have.

\section{Why Is This Study Being Done?}

The aim of this study is to establish quantitative data that will provide guidance for the need to implement improve or enhance existing beach safety education material for study abroad students. Ultimately it is hoped that this information will assist in reducing the number of study abroad student fatalities involving rip currents.

\section{Why Am I Being Asked To Be In This Study?}

You are being asked to be in this study because you participated in a study abroad between May 2013 and May 2015 as part of a program at Texas A\&M University.

\section{How Many People Will Be Asked To Be In This Study?}

We seek at least 500 people to complete this study.

\section{What Are The Alternatives To Being In This Study?}

The alternative to being in the study is not to participate. Participation in this study is not mandatory, and non-participation will not impact you in any fashion.

\section{What Will I Be Asked To Do In This Study?}

As a participant, you will be asked to be part of an anonymous online survey, which should require a time commitment of approximately ten minutes.

\section{Are There Any Risks To Me?}

The things that you will be doing are no greater than the risks than you would come across in everyday life. However, you do not have to answer anything you do not want to, and your participation may end at any time without any negative consequences.

\section{Will There Be Any Costs To Me?}

Aside from your time, there are no costs for taking part in the study. Depending on your internet connection speed, this research may take five to ten minutes of your time, and may take longer.

\section{Will Photos, Video Or Audio Recordings Be Made Of Me During The Study?}

No.

Will I Be Paid To Be In This Study?

You will not be paid for being in this study.

\section{Will Information From This Study Be Kept Private?}


The records of this study will be kept private. No identifiers linking you to this study will be included in any sort of report that might be published. Research records will be stored securely and only Sarah Trimble and Dr. Chris Houser will have access to the records. Information about you will be stored in a locked file cabinet in a private office. This consent form will be filed securely in an official area. All computer data, including uploaded documents, will be passwordprotected and encrypted. Information about you will be kept confidential to the extent permitted or required by law. People who have access to your information include the Principal Investigator and research study personnel. Representatives of regulatory agencies such as the Office of Human Research Protections (OHRP) and entities such as the Texas A\&M University Human Subjects Protection Program may access your records to make sure the study is being run correctly and that information is collected properly.

\section{Who may I Contact for More Information?}

You may contact the Principal Investigator, Dr. Chris Houser to tell him about a concern or complaint about this research at 979-845-3651 or chouser@tamu.edu. For questions about your rights as a research participant; or if you have questions, complaints, or concerns about the research, you may call the Texas A\&M University Human Subjects Protection Program office at 979-458-4067 or irb@tamu.edu.

\section{What if I Change My Mind About Participating?}

This research is voluntary and you have the choice whether or not to be in this research study. You may decide to not begin or to stop participating at any time. If you choose not to be in this study or stop being in the study, there will be no effect on your status, employment, or relationship with Texas A\&M University, etc. Any new information discovered about the research will be provided to you. This information could affect your willingness to continue your participation.

Question 1: I have read the informed consent document above and agree to participate in this research. This checkbox serves as a digital signature.

Agree (1)

Do not Agree (2)

If Do not Agree Is Selected, Then Skip To End of Survey

Question 2: In what year of school did you go on this trip?

a. Freshman year/first year (1)

b. Sophomore year/second year (2)

c. Junior year/third year (3)

d. Senior year/fourth year (4)

e. Super senior year/fifth year or later (5)

f. Graduate school (post undergraduate commencement) (6)

g. Other (7)

Question 3: What was your age at the start of this study abroad trip?

17 or younger (1)

18 (2)

19 (3) 
Question 4: What was your major when you went on this trip?

Question 5: What country or countries did you visit during your study abroad?

Question 6: Was the study abroad (select best fit)

faculty led (1)

part of a service trip (2)

an internship (3)

another program not led by a faculty member (4)

Question 7: How long was the study abroad program?

$<2$ weeks (1)

2 weeks to 1 month (2)

1-2 months (3)

2-6 months (4)

$>6$ months $(5)$

Question 8: Was the study abroad for credit?

Yes (1)

No (2)

Question 9: If the study abroad was for credit, please tell us the course title and number. If your study abroad was not for credit (e.g. non-credit bearing service learning, international internship, etc.) then please leave blank [Free answer]

Question 10: On this study abroad, did you visit a beach or beaches? **If you went on more than one study abroad, and went to a beach on any one of them, please answer "yes" and consider all following questions in reference to the trip or trips on which you did visit a beach. Yes (1)

No (2)

Question 11: How many beaches did you visit during your trip abroad?

$1(1)$

$2-5$ beaches $(2)$

$>5$ beaches (3)

Question 12: Was the beach (or beaches that) you visited on an ocean or a lake?

Ocean (1)

Sea (Black Sea, Mediterranean Sea, etc.) (2)

Lake (3) 
Both (for multiple beach visits) (4)

Question 13: In general, was the visit to the beach (or beaches) required, optional or both?

Required (1)

Optional (2)

Both (3)

Question 14: If you answered, "required", to Question 12 please describe how it was part of the course/program in which you were participating. For example, was the trip to the beach (or beaches) required for the collection of field data, a tour of the physical and or social landscape, or as designated recreation time?

Question 15: If you answered "optional" to Question 12 please describe how you or your group decided to visit that particular beach or beaches.

Question 16: In general, what was the main type of activity you did at the beach:

bathing and swimming (1)

board riding (surfboard, boogie board, paddle board, etc.) (2)

sunbathing only (no water entry) (3)

snorkeling (4)

measurements on the beach (5)

measurements in the water (6)

simple observations/lecture (7)

Question 17: In general, did you go to the beach alone or as part of a group?

I went to the beach alone (1)

As part of a group of 2-3 (2)

As part of a group of 4-5 (3)

As part of a group of 5-10 (4)

As part of a group $>10(5)$

Question 18: If you went as part of a group, was that group entirely made up of students and/or faculty on your study abroad?

Yes (1)

No (2)

Not applicable (I went alone) (3)

Question 19: If you answered no to the previous question (b, No)- meaning you went with a group not entirely made up of students or faculty members on your study abroad- who were the other members of the group?

They were other tourists/visitors, like me, just not on my study abroad trip. (1)

They were local or semi-permanent residents I had befriended. (2)

Other (3)

Not applicable (I went alone) (4) 
Question 20: Did you or your study abroad join/meet another group of students, tourists or locals that were already at the beach or any of the beaches that you visited?

No (1)

Locals (2)

Tourists (3)

Other study abroad students from a different program (4)

Question 21: Were you given any beach safety information before visiting the beach as part of the study abroad program or by the study abroad teachers/officials?

Yes (1)

No (2)

Don't know or remember (3)

Question 22: If you received beach safety information, can you describe the type of beach safety information you were given? Select all that apply.

Brochure (1)

Lecture/presentation (2)

Video (3)

Other (4)

Question 23: Do you remember seeing any beach safety information at the entrance to the beach or on the beach itself that was not provided to you by the study abroad officials?

Question 24: Do you remember seeing lifeguards at any of the beaches you visited?

Yes (1)

No (2)

Not at all beaches (3)

Question 25: Did you take any precautions before visiting a beach during your time abroad?

Yes (1)

No (2)

Not at all beaches (3)

Question 26: If you took precautions before visiting a beach can you describe the precautions that you took?

Question 27: Did you select the beaches that you visited based on the presence of lifeguards?

Yes (1)

No (2)

Not at all beaches (3)

Question 28: Did you take any precautions before entering the water?

Yes (1)

No (2)

Not at all beaches (3) 
Question 29: If you took precautions before entering the water at one or all beaches you visited, can you describe the precautions that you took?

Question 30: While at any of the beaches that you visited, did you experience any difficulty while swimming?

Yes (1)

No (2)

Don't remember (3)

Question 31: If you experienced difficulty while swimming, which of the following best describes your difficulty?

Large waves (1)

Strong currents (2)

Out of depth (3)

Jellyfish or other animal hazard (4)

Trash and other contaminants (5)

Emotional distress (6)

Other (7)

Question 32: Did you witness anyone/someone in your group who was in distress and clearly required rescue?

Yes (1)

No (2)

Question 33: If you witnessed someone else in distress or in need of rescue, which of the following describes their difficulty?

Large waves (1)

strong currents (2)

out of depth (3)

Jellyfish or other animal hazard (4)

trash and other contaminants (5)

Emotional discress (6)

Other (7)

Question 34: While experiencing this difficulty, what actions did you or someone else take to help them escape the situation?

Question 35: If you had to help/rescue someone did you feel comfortable and/or well-equipped to conduct the rescue?

Question 36: In retrospect, how would you describe the beach (or beaches) that you visited?

Safe for swimming (1)

Unsafe for swimming (2)

Unsure (3) 
Question 37: If you or someone in your group experienced difficulty in the water and needed rescue did this impact your future use of this and other beaches?

Question 38: Have you ever heard of rip currents (sometimes called rip tides)?

Yes (1)

No (2)

No but I have heard of undertow (3)

Question 39: Do you think that rip currents are visible (can be seen by someone standing on the beach)?

Yes (1)

No (2)

Not sure (3)

Question 40: If you were at a beach would you know how to spot a rip current?

Yes always (1)

Yes sometimes (2)

No (3)

Question 41: Where on this photograph would you feel most safe to enter the water? Click on the picture at the spot along the beach that you believe is the safest.

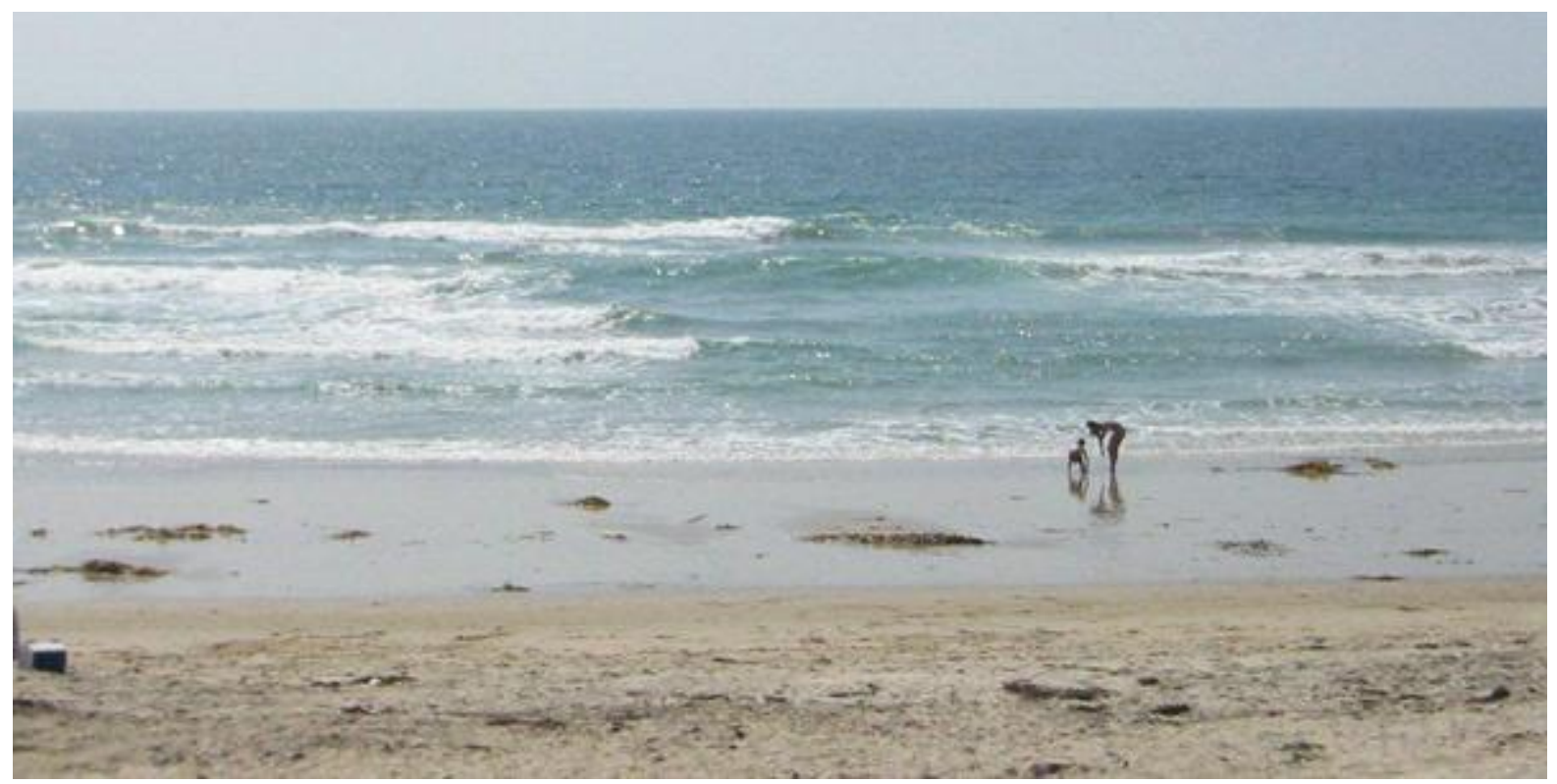


Question 42: Where on this photograph would you feel most safe to enter the water? Click on the picture at the spot along the beach that you believe is the safest.



Question 43: Where on this photograph would you feel most safe to enter the water? Click on the picture at the spot along the beach that you believe is the safest.

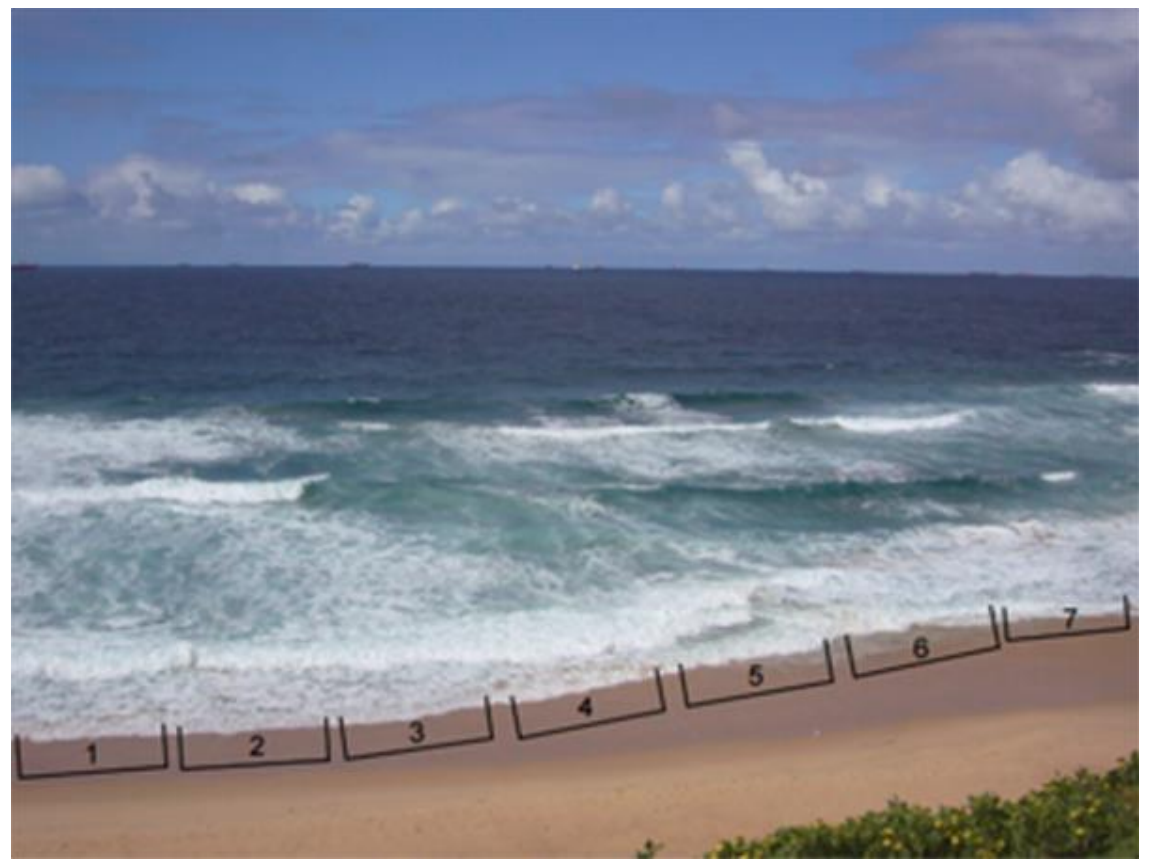


Question 44: Explain what you should do if caught in a rip current?

Question 45: Have you ever actually been caught in a rip current?

Yes once (1)

Yes more than once (3)

No (2)

Question 46: If you have been caught in a rip current, describe what happened.

Self-escaped by swimming parallel to the beach (1)

Float to safety (2)

Was rescued by a lifeguard (3)

Was rescued by a surfer/bystander (4)

Question 47: How often have you been to a beach prior to this study abroad?

I go to the beach less than once per decade (1)

I go to the beach once every few years (2)

I go to the beach about once a year (3)

I go to the beach multiple times during the year (4)

I go to the beach regularly (i.e,. several times a week during the summer) (5)

Never been to the beach prior to the trip (6)

Question 48: How far do you think you can swim in a pool before you have to stop/pause?

Less than 25 yards (one length of a typical community swimming pool) (1)

More than 25 yards but less than 100 yards (2)

More than 100 yards but less than 500 yards (3)

More than 500 yards (4)

I can't swim (5)

Question 49: How far do you think you can swim in open water with waves before you have to stop/pause?

Less than 25 yards (1)

More than 25 yards but less than 100 yards (2)

More than 100 yards but less than 500 yards (3)

More than 500 yards (4)

I can't swim (5)

Question 50: Which best describes your gender?

Male (1)

Female (2)

Prefer not to answer (3)

Question 51: What state in the United States are you from? This is not the same state as your school if you are an out-of-state student. If you are not from the United States, please list the country in which you live?

Question 52: If you are from the United States, what is your home zip code? 